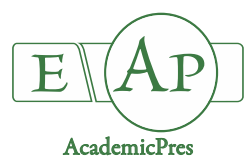

\title{
Some Biochemical Characteristics of Fruit Samples of Sambucus nigra Genotypes from Northeastern Turkey
}

\author{
Tuncay KAN \\ Turgut Ozal University, Faculty of Agriculture, Horticulture Department, Malatya, \\ Turkey;kantunca@gmail.com
}

\begin{abstract}
There are numerous wild edible fruit species in the world and they are important components of dietary utilization, local pharmacopoeia, cultural and religious practices of indigenous people. In this study, some important berry characteristics of seven seed propagated black elderberry (Sambucus nigra) genotypes sampled from Rize province, Turkey, were assessed. The genotypes exhibited a great diversity on most of the biochemical characteristics. Berries of genotypes showed moderate Vitamin C content ranged from 26 to $38 \mathrm{mg}$ per $100 \mathrm{~g}$ fresh weight. Total phenolic and total anthocyanin content in fruits of the $S$. nigra genotypes has also high value ranged from 360 to $447 \mathrm{mg}$ gallic acid equivalent (GAE) per $100 \mathrm{~g}$ fresh weight and 307 to $412 \mathrm{mg}$ cyanidin-3-glucoside equivalent per $100 \mathrm{~g}$ fresh berry, respectively. Antioxidant activity was found between 5.28 and $7.11 \mathrm{mmol}$ trolox equivalent per $100 \mathrm{~g}$ fresh weight basis. Citric acid and fructose determined as major organic acid and sugar for all genotypes. For its high vitamin C, total anthocyanin and total phenolic content and high antioxidant activity of fruits of wild grown $S$. nigra may have provide many health benefits and can be domesticated to establish orchards in Turkey.
\end{abstract}

Keywords: biochemical diversity; content; elderberry; less known fruits

\section{Introduction}

Horticultural plants present numerous types of species, cultivars, genotypes and accessions, occurring worldwide. The food industry is currently searching for new functional foods and nutraceuticals to help meet the demand presented by the consumers of natural, immunity-boosting and health-promoting plant based food product (Ercisli et al., 2011; Sengul et al., 2011; Zia-Ul-Haq et al., 2014).

Turkey, located between junctions of three important plant gene centers, exhibited a rich diversity of wild edible fruits. Wild edible fruits constitute major component of food sources and livelihood in particular for rural peoples for employment and income generation in inner, eastern and northern part of Turkey. Most of the wild edible fruits have also unique aroma and taste, which affects product quality (Ercisli et al., 2008; Vijayan et al., 2008).

Almost all wild edible fruits are naturally grown and gathered by rural people during maturation period from varied habitats including natural forests, pastures, agricultural fields, human disturbed areas such as roadsides and wastelands and utilization of certain wild plant foods is integral to their socio-cultural life (Cuce and Sokmen, 2017). They are consumed as substitute for staple food. In particular inner, northern and eastern part of Turkey, many rural families sells wild food plants in local market to generate cash income (Ercisli et al., 2008).

Sambucus nigra (black elderberry) is native to most of European and North American countries and generally known as medicinal plant. Because the flavour of the raw elderberry fruit is not acceptable to all tastes, though when cooked it makes delicious jams, preserves, pies etc. The dried elderberry fruit are less bitter. Elderberry fruit is about $8 \mathrm{~mm}$ in diameter and is borne in large clusters in late summer to early autumn. They are often used to make a sparkling wine. Sweet tea is made from the dried elderberry flowers (Veberic et al., 2009; Maja-Mikulic et al., 2016).

In literature, limited information is available about biochemical diversity of Sambucus nigra genotypes. Thus, in this study, we aimed to determine and compare some important biochemical features of Sambucus nigra genotypes naturally growing in Rize province located in Northeastern Turkey. 
554

\section{Materials and Methods}

\section{Plantmaterial}

Commercially ripe fruits of Sambucus nigra, naturally grown in Rize province situated Northeastern parts of Turkey were harvested. In commercial harvest period, black colored fruits were collected in autumn during the year 2017 from 7 pre-selected genotypes that show higher yield, pest and diseases free and more attractive bigger fruits.

\section{Biochemical and bioactive composition}

Sample preparation and extraction

For the organic acids, specific sugars, total phenolic, total anthocyanin contents and total antioxidant capacity analyses, harvested fruits immediately brought to the cooler state and stored at $-20{ }^{\circ} \mathrm{C}$ until further analyses. During analysis, the cold fruits were taken and thawed to room temperature. A laboratory blander used to homogenise fruit samples (100 g lots of fruits per genotypes) and a single extraction procedure (taking $3 \mathrm{~g}$ aliquots and transferring it inside tubes and extracted for one hour with $20 \mathrm{~mL}$ buffer including acetone, water (deionized), and acetic acid (70:29.5:0.5 v/v) (Singleton and Rossi, 1965).

\section{Extraction of sugars and organic acids}

Five grams samples slurries were mixed with deionized water or metaphosphoric acid (2.5\%) for the analysis of individual sugar and organic acid, respectively. The obtained homogenates were centrifuged at $10000 \mathrm{rpm}$ for $10 \mathrm{~min}$. The samples were filtered into HPLC vials using $0.45 \mu \mathrm{m}$ PTFE membrane filter for analysis. All HPLC solvents were sonicated. All samples and corresponding standard injection were repeated three times and the mean values were calculated.

\section{Chromatographic conditions}

The Perkin Elmer HPLC system controlled by software Totalchrom navigator (version 6.2.1), consists of a pump and UV detector was used for analysis of the samples. Organic acids separation and determination were performed as per the method reported by Shui and Leong (2002). The sugars were determined using the method of Bartolome et al. (1995) with help of HPLC with refractive index (RI) detector. The separation was carried out on SGE SS Exsil amino column $(250 \times 4.6 \mathrm{~mm}$ ID). The isocratic elution was performed using acetonitrile (80\%) and deionised water $(20 \%)$ with a flow rate of $0.9 \mathrm{~mL} / \mathrm{min}$. The column was operated at $30{ }^{\circ} \mathrm{C}$ and the sample injection volume was at $20 \mu \mathrm{L}$. Quantification of organic acids and sugars were performed against the reference standards.

\section{Total phenolic contents}

Total phenolic contents (TPC) of the samples were evaluated using the method of Singleton and Rossi (1965). In this procedure, each extract $(1 \mathrm{~mL})$ was mixed with Folin-Ciocalteu's reagent and water 1:1:20 (v/v). The samples were incubated for $8 \mathrm{~min}$. Then the addition of sodium carbonate $(10 \mathrm{~mL})$ having a concentration of $7 \%$ $(\mathrm{w} / \mathrm{v})$ was performed. After incubation for $2 \mathrm{~h}$, the absorbance at $750 \mathrm{~nm}$ was measured. Total phenolic contents were calculated against the reference standard calibration curve of gallic acid. The TPC was expressed as $\mathrm{mg}$ of gallic acid equivalents (GAE) per $100 \mathrm{~g}$ of sample (fresh weight (FW) basis).

\section{Total anthocyanin content}

Total anthocyanins contents were measured using a $\mathrm{pH}$ differential method of Giusti and Wrolstad (2001) with help of UV-visible spectrophotometer. The absorbance was measured both at 533 and $700 \mathrm{~nm}$ in buffers solution at $\mathrm{pH}$ 1.0 and 4.5. The total anthocyanins were calculated from the absorbance values and molar extinction coefficient value of 29,600. Total anthocyanins contents were expressed as $\mathrm{mg}$ of cyanidin-3-glucoside equivalent in per $100 \mathrm{~g}$ of fresh sample.

\section{Ferric reducing antioxidant power assay}

FRAP (Ferric reducing antioxidant power) assay was used for antioxidant capacity analysis. For this purpose, acetonic fruit extract $(50 \mu \mathrm{L})$, FRAP reagent $(2.95 \mathrm{~mL})$, acetate buffer $(0.1 \mathrm{~mol} / \mathrm{L}), \mathrm{TPTZ}(10 \mathrm{mmol} / \mathrm{L})$, and ferric chloride of $20 \mathrm{mmol} / \mathrm{L}(10: 1: 1 \mathrm{v} / \mathrm{v} / \mathrm{v})$ were used. The values of samples absorbance were compared with those of the reference standard calibration curves in the range of 10-100 $\mu \mathrm{mol} / \mathrm{L}$ of Trolox was used to determine FRAP values of samples. The FRAP was expressed as mmol per $100 \mathrm{~g}$ of Trolox equivalent on the basis of the fresh weight of fruits (Benzie and Strain, 1996).

\section{Statistical analysis}

All samples were five times replications for each experiment. For analysis of variance, the obtained data were used for means calculation. Duncan multiple range tests were performed at the significant level of $P<0.05$.

\section{Results and Discussion}

Ascorbic acid (Vitamin C), total phenolic content, total anthocyanin and total antioxidant capacity

Vitamin C (ascorbic acid), total phenolic content, the total anthocyanin, and total antioxidant capacity of fruit samples of Sambucus nigra genotypes are given in Table 1 . The genotypes showed vitamin $\mathrm{C}$ content between 26 and $38 \mathrm{mg}$ per $100 \mathrm{~g}$ fresh fruit weight and statistically significant differences $(\mathrm{p}<0.05)$ are evident (Table 1$)$. Previous studies indicated genotype/cultivar dependent vitamin $\mathrm{C}$ content of elderberry fruits. For example Mratinic and Fotiric (2007) reported vitamin C in elderberry fruit samples between $20-35 \mathrm{mg} / 100 \mathrm{ml}$ in Serbia. In Denmark, vitamin C content in 13 elderberry cultivars was reported between $6-25 \mathrm{mg} / 100 \mathrm{ml}$ (Kaack and Austed, 1998). In Czech Republic vitamin C was found average $26 \mathrm{mg}$ per $100 \mathrm{~g}$ (Porpaczy and Laszlo, 1984). Our values presented in Table 1 on vitamin $\mathrm{C}$ are between these limits.

The black elderberry genotypes are shown a wide variation on total phenolic content. Total phenolic content varied from $360 \mathrm{mg}$ GAE per $100 \mathrm{~g}$ to $447 \mathrm{mg}$ GAE per 100 g. Previous studies were also confirmed high total phenolic content of elderberry fruits. For example Lee and Finn (2007) reported 327-582 mg GAE/g total phenolic content in fresh Sambucus nigra fruits. Mikulic-Petkovsek et al. 
(2016) reported total phenolic content of elderberry fruit ranged from 268 to $683 \mathrm{mg}$ gallic acid equivalent (GAE) per $100 \mathrm{~g}$ fresh fruit in fruits of wild grown elderberry in Slovenia and they also found that total phenolic content is tightly connected with the contents of single phenolics. Our total phenolic content results are also in accordance with Lee and Finn (2007). Perkins-Veazie et al. (2015) reported total phenolics between 421-719 mg GAE per $100 \mathrm{~g}$ elderberry fresh fruits in USA.

Total anthocyanin content of elderberry genotypes statistically differed each other $(\mathrm{p}<0.05)$ and varied from $307 \mathrm{mg}$ to $412 \mathrm{mg}$ cyanidin-3-glucoside equivalent per 100 $\mathrm{g}$ fresh fruits (Table 1). The major anthocyanins in black elderberry fruits were reported as cyanidin-3-glucoside and cyanidin-3-sambubioside (Veberic et al., 2009). Veberic et al. (2009) reported total anthocyanin between 602-1265 mg per $100 \mathrm{~g}$ in fruits of elderberry genotypes, which indicated higher values than our samples. However, Bronnum-Hansen and Hansen (1983) found total anthocyanin content in 26 elderberry cultivars and genotypes ranged from 200 to $1000 \mathrm{mg}$ cy-3-glu/100 $\mathrm{g}$ fresh fruits and Lee and Finn (2007) reported between 140 to $280 \mathrm{mg}$ cy-3-glu/100 g fresh fruits. Perkins-Veazie et al. (2015) reported total anthocyanins between $85-385 \mathrm{mg}$ cy3-glu/100 g elderberry fresh fruits in USA.

The differences could be results of cultivars/genotypes used, genetic background, harvest period, different extraction methods, ecological conditions and sampling years. Sambucus is a diverse genus and there were incredible variation among species on most of the morphological and biochemical traits. These variations are more obvious in particular on total phenolic and anthocyanin anthocyanin content (Mikulic-Petkovsek et al., 2016). These results indicate total anthocyanin richness of black elderberry fruits and high polyphenol content of Sambucus nigra comparable with high anthocyanin included fruits such as black mulberry, cranberry, blueberry, black currant, blackberry and blue honeysuckle.

FRAP values of genotypes are shown in Table 1 and results indicated statistically significant differences $(p<$ 0.05 ) among genotypes in the total antioxidant capacities. Total antioxidant capacity was between 5.28 and 7.11 mmol/ 100 g. Halvorsen et al. (2002) reported average FRAP value in elderberry genotype grown in Norway was $5.24 \mathrm{mmol} / 100 \mathrm{~g}$. This value was $3.64 \mathrm{mmol} / 100 \mathrm{~g}$ for blueberry, $5.03 \mathrm{mmol} / 100 \mathrm{~g}$ for cranberry, $3.06 \mathrm{mmol} / 100$ $\mathrm{g}$ for raspberry and $2.17 \mathrm{mmol} / 100 \mathrm{~g}$ for strawberry, respectively (Halvorsen et al., 2002). The antioxidant capacity of Sambucus nigra fruit was quantified by a several methods, and all the results showed a very high antioxidant at very low concentrations (Veberic et al., 2009).

\section{Sugars}

Sugar content of Sambucus nigra genotypes are shown in Table 2. We found significant differences $(p<0.05)$ in specific sugar contents among black elderberry genotypes, as presented in Table 2. The major sugar for all black elderberry genotypes was fructose and followed by glucose. The sucrose values of all genotypes were found to be the lowest (Table 2). Fructose content of genotypes ranged from 40.11 to $50.42 \mathrm{~g}$ per $\mathrm{kg}$ fresh fruit samples. Glucose and sucrose content were between 38.24-48.36 and 9.54$11.22 \mathrm{~g}$ per $\mathrm{kg}$ fresh fruit samples (Table 2). The sugar content of the elderberry fruits used in this study is comparable to data reported for $S$. nigra fruits (Veberic et al., 2009; Thomas et al., 2015; Maja-Mikolic et al., 2016). A favorable fructose to glucose ratio $(1: 1)$ has been determined in elderberry fruits, which is in accordance to the report of Sadilova et al. (2009). The nutritional and health perspective, fruit with increased fructose levels should be favored by the consumers as this sugar tastes sweeter than glucose or sucrose and has a much lower glycemic index compared to other analyzed sugars (Atkinson et al., 2008). Elderberry fruit accumulates comparably low levels of total sugars $(47.19-109.16 \mathrm{~g} / \mathrm{kg}$ FW) than frequently consumed fruit such as apples (128.2$191.55 \mathrm{~g} / \mathrm{kg} \mathrm{FW)}$ (Mikulic-Petkovsek et al., 2007) and sweet cherry (177.91-242.87 g/kg FW) (Gundogdu and Bilge, 2012). Therefore, elderberry products (juice, syrups, jams etc.) represent an interesting supplement to human diet.

\section{Organic acids}

The organic acid contents of black elderberry fruits are shown in Table 3. As indicated in Table 3, black elderberry fruits had five major organic acids (citric, malic, tartaric, shikimic and fumaric acid). The concentration of citric, malic, tartaric, shikimic and fumaric acid ranged from 7.38 to $8.02 \mathrm{~g} / \mathrm{kg} \mathrm{FW} ; 5.12$ to $6.44 \mathrm{~g} / \mathrm{kg} \mathrm{FW} ; 1.63$ to $2.04 \mathrm{~g} / \mathrm{kg}$ FW; 0.22 to $0.39 \mathrm{~g} / \mathrm{kg} \mathrm{FW}$ and 0.14 to $0.31 \mathrm{~g} / \mathrm{kg} \mathrm{FW}$, respectively (Table 3 ).

Table 1. Vitamin C, total phenolics, total anthocyanins and antioxidant capacity in fruits of seven Sambucus nigra genotypes

\begin{tabular}{|c|c|c|c|c|}
\hline Genotypes & $\begin{array}{l}\text { Vitamin C } \\
(\mathrm{mg} / 100 \mathrm{~g})\end{array}$ & $\begin{array}{c}\text { Total phenol } \\
(\mathrm{mg} \mathrm{GAE} / 100 \mathrm{~g})\end{array}$ & $\begin{array}{c}\text { Total anthocyanin } \\
(\mathrm{mg} \text { cy-3-gluc } / 100 \mathrm{~g})\end{array}$ & $\begin{array}{c}\text { FRAP } \\
(\mathrm{mmol} / 100 \mathrm{~g})\end{array}$ \\
\hline Rl & $30 \mathrm{c}$ & $447 a$ & $366 b c$ & $7.11 \mathrm{a}$ \\
\hline $\mathrm{R} 2$ & $34 \mathrm{~b}$ & $424 b$ & $412 a$ & $6.84 \mathrm{~b}$ \\
\hline R3 & $26 \mathrm{~d}$ & $391 \mathrm{~cd}$ & $345 c$ & $5.86 \mathrm{~d}$ \\
\hline $\mathrm{R} 4$ & $29 \mathrm{~cd}$ & $410 \mathrm{bc}$ & $328 \mathrm{~cd}$ & $6.65 b c$ \\
\hline R5 & $34 \mathrm{~b}$ & $360 \mathrm{~d}$ & $383 b$ & $5.28 \mathrm{e}$ \\
\hline R6 & $38 \mathrm{a}$ & $383 \mathrm{~cd}$ & $358 \mathrm{bc}$ & $5.83 \mathrm{~d}$ \\
\hline R7 & $28 \mathrm{~cd}$ & $401 c$ & $307 d$ & $6.50 c$ \\
\hline
\end{tabular}

Different letters indicate the statistical difference within the same column among genotypes at $5 \%$ level. 
Table 2. Specific sugar content of Sambucus nigra genotypes (g/kg FW)

\begin{tabular}{cccc}
\hline Genotypes & Sucrose & Fructose & Glucose \\
\hline R1 & $10.05 \mathrm{ab}$ & $42.37 \mathrm{e}$ & $40.22 \mathrm{bc}$ \\
R2 & $10.76 \mathrm{ab}$ & $40.11 \mathrm{f}$ & $38.24 \mathrm{c}$ \\
R3 & $9.54 \mathrm{~b}$ & $44.34 \mathrm{~d}$ & $39.65 \mathrm{bc}$ \\
R4 & $9.86 \mathrm{ab}$ & $45.36 \mathrm{~cd}$ & $43.41 \mathrm{~b}$ \\
R5 & $10.41 \mathrm{ab}$ & $50.42 \mathrm{a}$ & $48.36 \mathrm{a}$ \\
R6 & $11.22 \mathrm{a}$ & $48.73 \mathrm{~b}$ & $45.22 \mathrm{ab}$ \\
R7 & $9.73 \mathrm{ab}$ & $46.44 \mathrm{c}$ & $43.88 \mathrm{ab}$ \\
\hline Different letters indicate the statistical difference within the same column among genotypes at 5\% level. & &
\end{tabular}

Table 3. Organic acid content of Sambucus nigra genotypes (g/kg FW)

\begin{tabular}{|c|c|c|c|c|c|}
\hline Genotypes & Citric & Malic & Tartaric & Shikimic & Fumaric \\
\hline R1 & $7.69 \mathrm{ab}$ & $5.44 b c$ & $1.77 \mathrm{~cd}$ & $0.22 b$ & $0.20 \mathrm{ab}$ \\
\hline $\mathrm{R} 2$ & $7.81 \mathrm{ab}$ & $5.12 c$ & $1.65 \mathrm{~d}$ & $0.39 \mathrm{a}$ & $0.27 \mathrm{ab}$ \\
\hline R3 & $7.90 \mathrm{ab}$ & $5.51 b c$ & $1.80 \mathrm{c}$ & $0.30 \mathrm{ab}$ & $0.14 b$ \\
\hline $\mathrm{R} 4$ & $7.38 \mathrm{~b}$ & $5.70 \mathrm{~b}$ & $2.04 a$ & $0.33 \mathrm{ab}$ & $0.22 \mathrm{ab}$ \\
\hline R5 & $7.44 a b$ & $6.06 a b$ & $1.86 \mathrm{bc}$ & $0.26 a b$ & $0.27 a b$ \\
\hline R6 & $8.02 \mathrm{a}$ & $6.21 \mathrm{ab}$ & $1.98 \mathrm{ab}$ & $0.33 \mathrm{ab}$ & $0.19 \mathrm{ab}$ \\
\hline R7 & $7.59 \mathrm{ab}$ & $6.44 a$ & $1.94 \mathrm{~b}$ & $0.37 \mathrm{a}$ & $0.31 \mathrm{a}$ \\
\hline
\end{tabular}

Mikulic-Petkovsek et al. (2016) determined four organic acids in the elderberry berries as citric acid, malic acid, shikimic acid and fumaric acid. They found that citric acid ( 3.11 to $4.81 \mathrm{~g} / \mathrm{kg} \mathrm{FW}$ ) was the most abundant organic acid in all cultivars/selections, followed by malic acid and smaller concentrations of shikimic and fumaric acid. Our results are indicating that elderberry fruit is exceptionally rich in citric acid. This is an important parameter for processing purposes. Compared to apple, (Hofer et al., 2005), sweet cherry (Usenik et al., 2008) and sour cherry (Bonerz et al., 2006), and justifies the leading role of the elderberry fruits for richness citric acid.

\section{Conclusions}

The results indicated that variation occurs for biochemical and bioactive characteristics in Sambucus nigra genotypes. To determine the superior genotypes of Sambucus nigra based on high bioactive content could increase the intake of health promoting compounds. These genotypes may be highly desirable in germplasm breeding programs to breed quality varieties of Sambucus nigra with high fruit size and antioxidant potential.

\section{References}

Atkinson FS, Foster-Powell K, Brand-Miller JC (2008). International tables of glycemic index and gycemic load values: 2008. Diabetes Care 31(12):2281-2283.

Benzie IFF, Strain JJ (1996). Ferric reducing ability of plasma (FRAP) as a measure of antioxidant power: The FRAP assay. Analytical Biochemistry 239(1):70-76.
Bartolome AP, Ruperez P, Fuster C (1995). Pineapple fruit: Morphological characteristics, chemical composition and sensory analysis of Red Spanish and Smooth Cayenne cultivars. Food Chemistry 53(1):75-79.

Bronnum-Hansen K, Hansen S (1983). High-performance liquid chromatographic separation of anthocyanins of Sambucus nigra $\mathrm{L}$. Journal ofChromatography 262:385-392.

Cuce M, Sokmen A (2017). In vitro production protocol of Vaccinium uliginosum L. (bog bilberry) growing in the Turkish flora. Turkish Journal of Agriculture and Forestry 41(4):294-304.

ErcisliS, Akbulut M, Ozdemir O, Sengul M, Orhan E (2008). Phenolic and antioxidant diversity among persimmon (Diospyrus kaki L.) genotypes in Turkey. International Journal of Food Science and Nutrition 59(6):477-482.

Ercisli S, Ipek A, Barut E (2011). SSR marker-based DNA fingerprinting and cultivar identification of olives (Olea europae). Biochemical Genetics 49(9-10):555-561.

Giusti MM, Wrolstad RE (2001). Characterization and measurement of anthocyanins by UV-visible spectroscopy. Current Protocols in Food Analytical Chemistry 1:F1-2.

Gundogdu M, Bilge U (2012). Determination of organics, phenolics, sugars and vitamin C contents of some cherry cultivars (Prunus avium). International Journal of Agriculture and Biology 14(4):595-599.

Halvorsen BL, Holte K, Myhrstad MCW, Barikmo I, Hvattum E, ... Blomhoff $R$ (2002). A systematic screening of total antioxidants in dietary plants. The Journal of Nutrition 132(3):461-471.

Hofer M, Grill D, Hecke K, Herbinger K, Keppel H, ... Veberic R (2005). Inhaltsstoffe alter Apfelsorten unter diätetischem Aspekt-Schwerpunkt Diabetes. Journal für Ernährungsmedizin 7(1):30-33. 
Kaack K, Austed T (1998). Interaction of vitamin C and flavonoids in elderberry (Sambucus nigra L.) during juice processing. Plant Foods for Human Nutrition 52(3):187-198.

Lee J, Finn CE (2007). Anthocyanins and other polyphenolics in American elderberry (Sambucus canadensis) and European elderberry (S. nigra) cultivars. Journal of the Science of Food and Agriculture 87(14):26652675.

Mikulic-Petkovsek M, Stampar F, Veberic R (2007). Parameters of inner quality of the apple scab resistant and susceptible apple cultivars (Malus domestica Borkh.). Scientia Horticulturae 114(1):37-44.

Mikulic-Petkovsek M, Ivancic A, Schmitzer V, Veberic R, Stampar F (2016). Comparison of major taste compounds and antioxidative properties of fruits and flowers of different Sambucus species and interspecific hybrids. Food Chemistry200:134-140.

Mratinic E, Fotiric M (2007). Selection of black elderberry (Sambucus nigra L.) and evaluation of its fruits usability as biologically valuable food. Genetika 3(3):305-314.

Perkins-Veazie P, Thomas AL, Byers PL, Finn CE (2015). Fruit composition of elderberry (Sambucus spp.) genotypes grown in Oregon and Missouri, USA. Acta Horticulturae 1061:219-224.

Porpaczy A, Laszlo M (1984). Evaluation of elderberry (Sambucus nigra L.) clones based on the quality of the fruit. Acta Alimentaria 13:109-115.

SadilovaE, StintzingFC, Kammerer DR, Carle R(2009). Matrix dependent impact of sugar and ascorbic acid addition on color and anthocyanin stability of black carrot, elderberry and strawberry single strength and from concentrate juices upon thermal treatment. Food Research International 42(8):1023-1033.
Sengul M, Ercisli S, Yildiz H, Gungor N, Kavaz A, Cetin B (2011). Antioxidant, antimicrobial activity and total phenolic content with the aerial parts of Artemisia absinthum, Artemisia santonicum and Saponaria officinalis. Iranian Journal of Pharmaceutical Research 10(1):49-55.

Shui G, LeongSL (2002). Separation and determination of organic acids and phenolic compounds in fruit juices and drinks by high-performance liquid chromatography.Journal Chromatography A 977(1):89-96.

Singleton VL, Rossi JA (1965). Colorimetry of total phenolics with phosphomolybdic-phosphotungstic acid reagents. American Journal of Enology and Viticulture 16(3):144-158.

Thomas AL, Byers PL, Gu S, AveryJD, Kaps M,... Rottinghaus GE (2015). Occurrence of polyphenols, organic acids, and sugars among diverse elderberry genotypes grown in three Missouri (USA) locations. Acta Horticulturae 1061:147-153.

Usenik V, Fabcic J, Stampar F (2008). Sugars, organic acids, phenolic composition and antioxidant activity of sweet cherry (Prunus avium L.). Food Chemistry 107(1):185-192.

Veberic R, Jakopic J, Stampar F, Schmitzer V (2009). European elderberry (Sambucus nigra L.) rich in sugars, organic acids, anthocyanins and selected polyphenols. Food Chemistry 114(2):511-515.

Vijayan K, Chakraborti SP, Ercisli S, Ghosh PD (2008). NaCI induced morpho-biochemical and anatomical changes in mulberry (Morus spp.). Plant Growth Regulation 56(1):61-69.

Zia-Ul-Haq M, Ahmad S, Bukhari SA, Amarowicz R, Ercisli S, Jaafar HZE (2014). Compositional studies and biological activities of some mash bean (Vigna mungo (L.) Hepper) cultivars commonly consumed in Pakistan. Biological Research 47(1):23. 